\title{
Studies on Parkinson's-Disease-Linked Genes, Brain Urea Levels and Histopathology in Rotenone Induced Parkinson's Disease Rat Model
}

\author{
Suchitra Kavuri ${ }^{1,2^{*}}$, Senthilkumar Sivanesan ${ }^{1 * \#, ~ M a t h e w ~ D . ~ H o w e l l ~}{ }^{3}$, \\ Rajagopalan Vijayaraghavan', Jayakumar Rajadas ${ }^{4,5}$
}

\author{
${ }^{1}$ Department of Research and Development, Saveetha Institute of Medical and Technical Sciences, Chennai, India \\ ${ }^{2}$ Department of Biochemistry, Alluri Sitarama Raju Academy of Medical Sciences, Eluru, India \\ ${ }^{3}$ Biomedical Editor, St. Petersburg, FL, USA \\ ${ }^{4}$ Biomaterials and Advanced Drug Delivery Laboratory, Stanford University School of Medicine, Stanford, CA, USA \\ ${ }^{5}$ Department of Bioengineering and Therapeutic Sciences, School of Pharmacy and Medicine, University of California San \\ Francisco, San Francisco, CA, USA \\ Email: suchikavuri@gmail.com, \#senbio@gmail.com, howell.md001@gmail.com, jai_vijay@hotmail.com, jayraja@stanford.edu
}

How to cite this paper: Kavuri, S., Sivanesan, S., Howell, M.D., Vijayaraghavan, R. and Rajadas, J. (2020) Studies on Parkinson's-Disease-Linked Genes, Brain Urea Levels and Histopathology in Rotenone Induced Parkinson's Disease Rat Model. World Journal of Neuroscience, 10, 216-234. https://doi.org/10.4236/wjns.2020.104021

Received: October 28, 2020

Accepted: November 24, 2020

Published: November 27, 2020

Copyright (๑) 2020 by author(s) and Scientific Research Publishing Inc. This work is licensed under the Creative Commons Attribution International License (CC BY 4.0).

http://creativecommons.org/licenses/by/4.0/

\begin{abstract}
Parkinson's disease (PD) is a debilitating neurological disorder that affects the aged population globally. This study aimed to explore how oral- and intraperitoneal-rotenone-induced PD alters brain urea levels, histopathology, and key Parkinsonism-related genes in the striatum. Hematoxylin and eosin staining was performed for histopathology assessment and real-time polymerase chain reaction was performed for gene expression. Rotenone $3 \mathrm{mg} / \mathrm{kg}$ body weight (Rot-3-ip) for 21 days and rotenone $50 \mathrm{mg} / \mathrm{kg}$ body weight (Rot-50-po) for 28 days significantly $(\mathrm{p}<0.05)$ altered alpha-synuclein and tyrosine hydroxylase protein expression and Snca, Becnl and Prkaal gene expression in the striatum. Lewy bodies were visible in both Rot-3-ip and Rot-50-po rat brains. There were contrasting features in brain and liver histopathology between the oral and intraperitoneal rotenone treatment groups. However, there was no significant $(\mathrm{p}<0.05)$ difference in the brain urea levels between intraperitoneal and oral rotenone treatment groups. The propagation of PD through oral and intraperitoneal rotenone can have different impacts on the pathological sequence of events based on the molecular approach.
\end{abstract}

\section{Keywords}

Parkinson's Disease, Rotenone Intraperitoneal and Oral, Brain Urea, Alpha-Synuclein, Beclin-1, AMP-Activated Protein Kinase, Brain and Liver Pathology

*These authors contributed equally. 


\section{Introduction}

Parkinson's disease (PD), the second most common neurodegenerative disorder, features motor and non-motor symptoms. It is a progressive disease characterized by basal ganglia dysfunction caused by degeneration of dopaminergic neurons in the substantia nigra pars compacta $(\mathrm{SNpc})$ and development of fibrillar cytoplasmic inclusions that contain alpha synuclein ( $\alpha$-syn) and ubiquitin [1] [2]. Many pivotal works have plausibly linked autophagy [3] [4] [5] and mitochondrial energy dysfunction [6] [7] with PD. In other neurodegenerative conditions, including Alzheimer's disease (AD) and Huntington's disease (HD), brain urea levels are elevated, although the relative cause for these changes is unknown. Some authors have speculated that $\mathrm{PD}$ originates outside of the central nervous system (CNS) through some involvement with the enteric nervous system (ENS, [8] [9]).

Mitochondrial dysfunction is widely considered to play a major role in the underlying mechanisms contributing to neurodegeneration in PD [10].

Chronic inflammation is also attributed chiefly to the pathogenesis of several neurodegenerative diseases, including Alzheimer's disease (AD) and PD. Recent work has implicated NLR family pyrin domain containing 3 (NLRP3) "inflammasomes" in PD progression. Specifically, inflammasome activation could lead to proteolytic activation of caspase- 1 to promote cleavage of pro-interleukin (IL) $-1 \beta$ and the secretion of proinflammatory cytokines such as IL- $1 \beta$ and IL-18 [11] [12].

Researchers have reported a link between many dysregulated genes and PD pathogenesis. Some of these genes aberrantly affect mitochondrial dynamics/ homeostasis and energy functions (parkin $[$ Prkn], phosphatase and tensin homolog-induced kinase 1 [Pink1], components of adenosine monophosphate-activated protein kinase $[\mathrm{AMPK}]$, and peroxisome proliferator-activated receptor gamma coactivator 1-alpha [Ppargcla]). Other genes are involved in autophagyendo-lysosomal processes (beclin-1 [Becn1] and microtubule-associated proteins 1A/1B light chain 3B [Map1 lc3b], GAK (cyclin G-associated kinase), GBA (glucosylceramidase beta), FBX07 (F-box only protein 7) [13], or are markers of neurodegeneration during PD progression (leucine-rich repeat kinase 2 [Lrrk2] and $\alpha$-Syn [Snca]) [14] [15]. Impaired microglial autophagy triggers dopaminergic neurodegeneration both in vitro and in vivo by regulating NLRP3 inflammasome activation in experimental models of Parkinson's disease [16].

The toxin rotenone, either injected unilaterally into the brain-into the right striatum or right substantia nigra-or systemically through the subcutaneous or intraperitoneal route of administration, causes PD, denoted by the loss of dopaminergic neurons and striatal dopamine content and elevated $\alpha$-synuclein accumulation [17]. Several mechanisms are involved in the PD induced by rotenone, including impairment of the mitochondrial respiratory chain, microglia activation, the formation of reactive oxygen species that promote autooxidation, and dopaminergic neuronal apoptosis [18] [19] [20]. Based on previous research, 
rotenone-induced PD models replicate some experimental features of idiopathic $\mathrm{PD}$, namely slow and progressive damage to dopaminergic neurons and Lewy body formation in the nigrostriatal pathway [21]. Rotenone also aggravates the $\mathrm{PD}$ features in the gut by disrupting the colonic expression of the tight junction protein zonula occludens-1 (ZO-1), elevating oxidative stress (denoted by $\mathrm{N}$-tyrosine), and increasing the expression of glial fibrillary acidic protein (GFAP) in the myenteric plexus and $\alpha$-syn in the colon. These changes implicate a dysfunctional microbiota-gut-brain axis [22].

Researchers have suggested that when rotenone is administered systemically, it causes more damage in the striatum and globus pallidus regions of brain [23]. Other interesting works have focused on the striatal region of brain to evaluate rotenone-induced toxicity and PD pathogenesis [24]. Hence, in the present work we focused on the corpus striatum to evaluate the effects of different modes of rotenone administration on the PD etiology. Rodent rotenone models of PD have been widely employed to explore molecular mechanisms involved in the disease pathogenesis and to test the efficacy of several therapeutic interventions/drugs [25] [26] [27] [28]. However, it is unknown whether oral and intraperitoneal rotenone administration promotes the same PD pathogenesis. In our earlier investigations, we explored how intraperitoneal and oral rotenone toxicity altered various hematological and oxidative stress parameters in rats [29] [30]. To this end, we explored whether oral and intraperitoneal rotenone treatment induced a similar PD-like progression. We examined various gene expression changes, histopathological and immunohistochemical as well as urea levels in brain samples.

\section{Materials and Methods}

\section{Animals}

Male Wistar rats, weighing 250 - 300 g, were housed in solid-bottomed polypropylene cages at $22^{\circ} \mathrm{C} \pm 1{ }^{\circ} \mathrm{C}, 30 \%-40 \%$ relative humidity, and a $12 \mathrm{~h}$ light: $12 \mathrm{~h}$ dark photoperiod. All rats had free access to food and water. This study conformed to the guiding principles of the Institutional Animal Ethics Committee (IAEC) and was approved by the Institutional Animal Ethical Committee of Saveetha Medical College (IAEC Approval Number SU/CLAR/RD/014/2015).

\section{$\mathrm{PD}$ induction in rats}

For intraperitoneal administration, rotenone was prepared as previously described [31] with modifications. Rotenone (0.0315 g; TCI America) was first dissolved in $250 \mu \mathrm{L}$ dimethyl sulfoxide (DMSO) and subsequently diluted with $21 \mathrm{~mL}$ olive oil. Rats were injected with $3 \mathrm{mg} / \mathrm{kg}$ body weight (bw; Rot-3-ip). Rat weights were recorded daily, and the volume of injected rotenone was adjusted to provide the appropriate dose. Control rats (Con-OO) were injected with 2 $\mathrm{mL} / \mathrm{kg}$ bw olive oil. The solutions were prepared fresh weekly in amber colored bottles and vortexed before each intraperitoneal injection to avoid settling. The solutions were stored at $4^{\circ} \mathrm{C}$.

We performed oral dose preparation and administration according to Inden 
et al. [32] with modifications. Rotenone (0.525 g) was dissolved in $63 \mathrm{~mL} \mathrm{0.5 \%}$ hydroxypropyl cellulose (HPC; HiMedia, Mumbai, India). Rats were administered $50 \mathrm{mg} / \mathrm{kg}$ bw. The solutions were prepared fresh weekly and vortexed several times before each oral administration to avoid settling. Control rats (ConHPC) were administered only $0.5 \%$ HPC ( $5 \mathrm{~mL} / \mathrm{kg} \mathrm{bw}$ ) orally for 28 days. The randomly selected male Wistar rats were equally divided into four groups as follows:

Group I $(\mathrm{n}=6)$ : rats received daily intraperitoneal olive oil (vehicle; $2 \mathrm{~mL} / \mathrm{kg}$ bw) for 21 days;

Group II $(\mathrm{n}=6)$ : rats received daily intraperitoneal rotenone $(3 \mathrm{mg} / \mathrm{kg} \mathrm{bw})$ for 21 days;

Group III $(\mathrm{n}=6)$ : rats received daily oral $0.5 \% \mathrm{HPC}$ (vehicle $5 \mathrm{~mL} / \mathrm{kg} \mathrm{bw}$ ) for 28 days; and

Group IV $(\mathrm{n}=6)$ : rats received daily oral rotenone $(50 \mathrm{mg} / \mathrm{kg} \mathrm{bw})$ for 28 days.

During the experimental period, all animals were carefully observed twice daily for clinical and distress signs. While two rats from the Rot-3-ip group died during rotenone treatment, there was no mortality observed in the remaining groups. Additional rats were used to maintain a constant number of animals ( $\mathrm{n}$ $=6$ ) in the Rot-3-ip group due to the mortality. After completing the treatment protocol, the rats were anesthetized with isoflurane. Brain and liver tissue samples were dissected and used for further analysis.

\section{Preparation of tissue homogenates}

One-hundred milligrams brain tissue was homogenized in $5 \mathrm{~mL} 0.1 \mathrm{M}$ Tris- $\mathrm{HCl}$ buffer ( $\mathrm{pH} 7.4$ ) at $4^{\circ} \mathrm{C}$ in a tissue homogenizer with a Teflon pestle at $600 \mathrm{rpm}$ for $5 \mathrm{~min}$. The homogenate was centrifuged at $3000 \mathrm{~g}$ for $10 \mathrm{~min}$ at $4^{\circ} \mathrm{C}$ using a Remi refrigerated centrifuge. The supernatant was used for the urea analysis.

\section{Histopathological analysis}

To assess cellular changes, small sections of liver and brain from control and rotenone-treated rats were collected. They were washed with ice-cold $0.9 \%$ saline and fixed in neutral buffered formalin (10\%) for $24-48 \mathrm{~h}$. After fixation, tissues were dehydrated in ascending grades of alcohol and embedded in wax following standard techniques. Five-to-seven micrometer thick paraffin sections were cut and then subjected to hematoxylin and eosin (H\&E) staining. The pathological changes were viewed under a light microscope (Olympus CX23) by a pathologist who was blind to the groups.

\section{Immunohistochemistry}

Rats in each group were anesthetized with isoflurane, euthanized, and brain tissue was immediately dissected. Tissues from each group were immersed in the fixative solution for $4 \mathrm{~h}$. The tissues were cryoprotected in $30 \%$ sucrose, embedded in tissue-freezing medium with liquid nitrogen, and sectioned at 3 - $5 \mu \mathrm{m}$ using a cryostat. Sections were stored under anti-freeze buffer. Parallel freefloating sections were subjected to endogenous peroxidase quenching with $1 \%$ hydrogen peroxide in phosphate-buffered saline (PBS), followed by treatment with blocking buffer (5\% normal chicken serum and $0.3 \%$ Triton X-100 in PBS overnight at $4^{\circ} \mathrm{C}$ ) to block nonspecific protein binding. Sections were incubated 
with mouse anti- $\alpha$-syn or mouse anti-tyrosine hydroxylase overnight at $4^{\circ} \mathrm{C}$. After washing with PBS, tissues were incubated with a biotinylated goat anti-mouse secondary antibody for $2 \mathrm{~h}$ at room temperature. The tissues were subsequently exposed to an avidin-biotin peroxidase complex for $2 \mathrm{~h}$. Labeled proteins were visualized using a stable diaminobenzidine solution. All immunoreactions were observed using a compound light microscope, and the results were quantified using ImageJ 1.46 (National Institutes of Health, Bethesda, MD, USA). For quantification, fragmentation (F) reflects that $\alpha$-syn expression (brown patches in the image) appeared as either single, homogeneous, and continuous; or complex, heterogeneous, and discontinuous patches in the image. Based on this protein expression classification, fragmentation $(F)$ was calculated as: $F=N / A$, where $\mathrm{N}$ is the number of protein expression patches in the image and $\mathrm{A}$ is the total area (in pixels) of the protein.

\section{Reverse-transcription polymerase chain reaction (RT-PCR)}

Total RNA from tissues was isolated according to the RNA isolation kit instructions. Briefly, $50 \mathrm{mg}$ minced tissue isolated from the corpus striatum was homogenized in $350 \mu \mathrm{L}$ lysis solution. The homogenate was centrifuged for $5 \mathrm{~min}$ at $13,000 \mathrm{~g}$, and the supernatant was transferred to a fresh microcentrifuge tube. Three-hundred-fifty microliters $70 \%$ ethanol was added to the lysate, and the solution was completely mixed with gentle and repeated inversions. Total RNA was extracted from the tissues using a guanidinium-thiocyanate-phenol-chloroform single-step extraction kit (Invitrogen). Following precipitation, RNA was resuspended in RNase-free Tris-ethylenediaminetetraacetic acid (TE) buffer; the concentration was estimated by absorbance at $260 \mathrm{~nm}$. RNA quality was determined by agarose-formaldehyde electrophoresis [33]. RNA samples were stored at $80^{\circ} \mathrm{C}$ until analysis. Single-strand complementary DNA (cDNA) was generated from 5 $\mu \mathrm{g}$ total RNA using oligo-(dT) primers. RT-PCR were $50 \mu \mathrm{L}$ reactions with $2 \mu \mathrm{L}$ cDNA, 2 U Taq polymerase, $200 \mu \mathrm{M}$ each deoxynucleotide (dATP, dCTP, dGTP, and dTTP), $1.5 \mathrm{mM} \mathrm{MgCl}_{2}, 5 \mu \mathrm{L} \mathrm{10 \times} \mathrm{PCR} \mathrm{buffer}(50 \mathrm{mM} \mathrm{KCl}$ and $10 \mathrm{mM}$ Tris-HCl, $\mathrm{pH}$ 8.3) and specific primers (synthesized by GIBCO BRL/Life Technologies) used at a final concentration of $1 \mathrm{mM}$. Gene-specific primers (Table 1) were used to amplify Snca [34], Becn1 [35], and Prkaal (encodes AMPK- $\alpha$; [36]) in the striatum. The housekeeping genes $A c t b$ ( $\beta$-actin) or Gapdh (glyceraldehyde 3-phosphate dehydrogenase) were used to assess PCR quality and normalize the results.

PCR was performed in a thermal cycler (Perkin-Elmer-Cetus, Norwalk, CT); the thermal cycling conditions varied based on the amplified genes. For Snca and $A c t b$, there were 35 cycles of denaturation at $94^{\circ} \mathrm{C}$ for $1 \mathrm{~min}$, annealing at $58^{\circ} \mathrm{C}$ for $30 \mathrm{sec}$, and extension at $72^{\circ} \mathrm{C}$ for $45 \mathrm{sec}$. For Becnl and $A c t b$, there were 40 cycles of denaturation at $95^{\circ} \mathrm{C}$ for $30 \mathrm{sec}$, annealing at $60^{\circ} \mathrm{C}$ for $45 \mathrm{sec}$, and extension at $72^{\circ} \mathrm{C}$ for $2 \mathrm{~min}$. For Prkaal and Gapdh, there were 35 cycles of denaturation at $95^{\circ} \mathrm{C}$ for $30 \mathrm{sec}$, annealing at $60^{\circ} \mathrm{C}$ for $45 \mathrm{sec}$, and extension at $72^{\circ} \mathrm{C}$ for $45 \mathrm{sec}$.

PCR products were separated by electrophoresis on a $1.5 \%$ agarose gel that 
Table 1. List of primers used for RT-PCR.

\begin{tabular}{|c|c|c|c|}
\hline Gene & Forward primer $\left(5^{\prime} \rightarrow 3^{\prime}\right)$ & Reverse Primer $\left(5^{\prime} \rightarrow 3^{\prime}\right)$ & $\begin{array}{l}\text { Product } \\
\text { Size (bp) }\end{array}$ \\
\hline Snca & AGAAGACCAAAGAGCAAGTG & ATCTGGTCCTTCTTGACAA & 218 \\
\hline$A c t b$ (for $S n c a)$ & TGAGAGGGAAATCGTGCGTG & TGCTTGCTGATCCACATCT & 139 \\
\hline Becnl & CTTACCACAGCCCAGGCGAAAC & GCCAGAGCATGGAGCAGCAA & 814 \\
\hline$A c t b($ for $B e c n 1)$ & TGACGGGGTCACCCACACTGTGCC & CTTAGAAGCATTGCGGTGGACGATG & 666 \\
\hline Prkaal & GTCGGCGTCTGTTCCAACAGA & СССТСТTCATGGGATCCACCT & 263 \\
\hline Gapdh & CCACCCATGGCAAATTCCATGGC & TCTAGACGGCAGGTCAGGTCCACC & 200 \\
\hline
\end{tabular}

contained ethidium bromide. The gel was then photographed under UV transillumination, and the intensity of the PCR products was measured using an image analysis system (Kodak Digital Science). The relative amount of each target gene was normalized to the reference gene ( $A c t b$ or $G a p d h)$, and the results are expressed as the ratio of target to reference transcripts.

Estimation of the striatal urea content

To measure the urea content, dissected brains were immediately washed in ice-cold PBS and weighed. Twenty milligrams tissue taken from the corpus striatum was homogenized in $100 \mu \mathrm{L}$ Urea Assay Buffer (Elabscience Diagnostic kit) and centrifuged at $15,000 \mathrm{~g}$ for $10 \mathrm{~min}$ to remove insoluble material. Fifty microliters of each sample or control was added to the wells of a microtiter plate. Next, a $50 \mu \mathrm{L}$ reaction mix that contained $42 \mu \mathrm{L}$ urea assay buffer, $2 \mu \mathrm{L}$ oxiRed probe, $2 \mu \mathrm{L}$ enzyme mix, $2 \mu \mathrm{L}$ developer, and $2 \mu \mathrm{L}$ converter enzyme was added to the wells of a 96-well microtiter plate. The contents of each well were mixed and incubated for $60 \mathrm{~min}$ at $37^{\circ} \mathrm{C}$ protected from light. The optical density (OD) at 570 $\mathrm{nm}$ was measured with a microplate reader (Mindray MR-96A). Urea content was determined from urea standards that were included on the assay plate.

\section{Statistical analysis}

The RT-PCR and immunohistochemistry data are expressed as the mean \pm standard error of the mean; the urea measurements are expressed as the mean \pm standard deviation. The statistical analysis was carried out by employing oneway analysis of variance (ANOVA) followed by the Bonferroni or StudentNewman-Keul multiple comparison test ( $p<0.05$ was considered significant). The statistical analysis was performed using the following software programs: RT-PCR, R version 3.6.3; immunohistochemistry quantification, SPSS version 22.0 (IBM Corp., Armonk, NY, USA); and urea measurements, Sigma plot 13 (Systat Software, San Jose, CA, USA).

\section{Results}

Gene expression analysis in the brain of intraperitoneal- or oral-rotenone-induced rats

To determine the relative efficacy of intraperitoneal and oral rotenone administration, we used RT-PCR to examine the expression of genes implicated in PD 
pathology. Snca was upregulated 1.7 fold in the Rot-50-po compared with the Con-HPC striatum and more than 2 fold in Rot-3-ip compared with Con-OO striatum (Figure 1(A), Figure 1(B)).

Becnl encodes the protein beclin-1, a major player in autophagy that has been implicated in neurodegenerative diseases including PD [37]. In addition, autophagy flux is impaired in a rotenone-induced PD cell model [38]. We thus assessed the relative effect of intraperitoneal and oral rotenone administration on striatal Becn1. It was upregulated 3 fold in the Rot-3-ip compared with the Con-OO striatum, but it was only 1.5 fold higher in the Rot-50-po compared with the Con-HPC striatum (Figure 2(A), Figure 2(B)).

AMPK is involved in cellular energy regulation, especially when cellular energy levels are reduced. However, AMPK activation may exacerbate PD pathology. We analyzed the gene expression of the AMPK $\alpha$ l subunit (Prkaal) after intraperitoneal and oral rotenone treatment (Figure 3(A), Figure 3(B)). Rot-3-ip
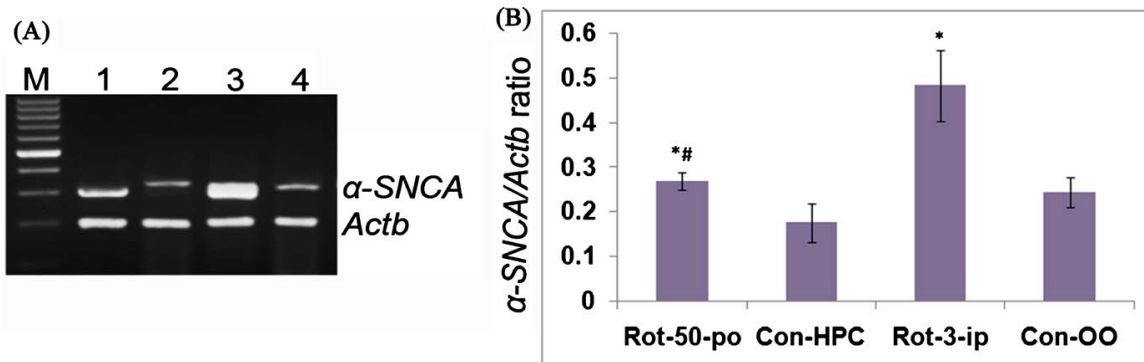

Figure 1. Snca gene expression in the striatum of control and rotenone-treated groups. Representative agarose gels of reverse-transcription polymerase chain reaction (RT-PCR) products from the striatum ((A) and (B)). Quantification of gel bands, expressed as the Sncal $A c t b$ ratio ( $\mathrm{n}=6$ rats per group). Lane identities: M, Marker (100 - 1000 bp); 1, Rotenone $50 \mathrm{mg} / \mathrm{kg}$ body weight oral (Rot-50-po); 2, Control hydroxy propyl cellulose (Con-HPC); 3, Rotenone $3 \mathrm{mg} / \mathrm{kg}$ body weight intraperitoneal (Rot-3-ip); 4, Con-OO (Control olive oil). Statistical analysis: ${ }^{\star} \mathrm{p}<0.01$ compared with Con-OO; ${ }^{\star *} \mathrm{p}<0.05$ compared with Con-HPC.
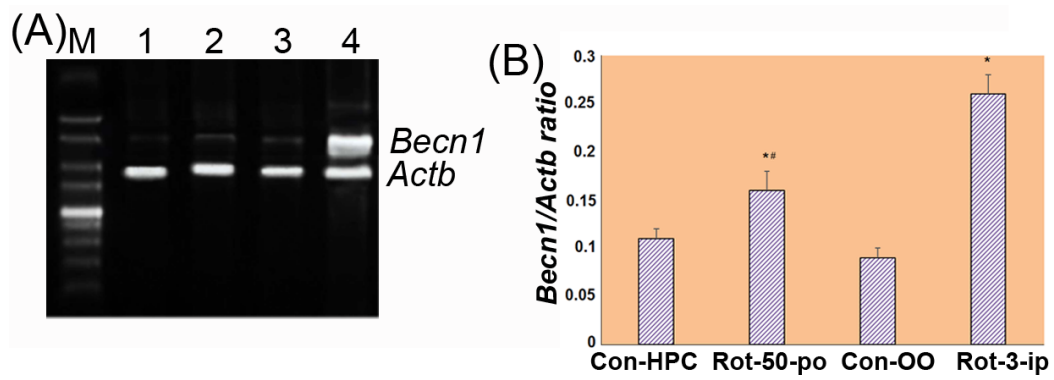

Figure 2. Becnl gene expression in the striatum of control and rotenone-treated groups. (A) Representative agarose gel of reverse-transcription polymerase chain reaction (RTPCR) products for Becnl and $A c t b$ (loading control). (B) Quantification of gel bands, expressed as the $B e c n 1 / A c t b$ ratio ( $\mathrm{n}=6$ rats per group). Lane identities: M, Marker (100 $1000 \mathrm{bp}$ ); 1, Control hydroxy propyl cellulose (Con-HPC); 2, Rotenone $50 \mathrm{mg} / \mathrm{kg}$ body weight oral (Rot-50-po); 3, Control olive oil (Con-OO); 4, Rotenone $3 \mathrm{mg} / \mathrm{kg}$ body weight intraperitoneal (Rot-3-ip). Statistical analysis: ${ }^{\star} \mathrm{p}<0.01$ compared with Con-OO; ${ }^{*} \mathrm{p}<$ 0.05 compared with Con-HPC. 
upregulated Prkaal 4 fold compared with the Con-OO striatum. Comparatively, Rot-50-po increased Prkaal 2 fold compared with the Con-HPC striatum. Overall, intraperitoneal rotenone had a stronger effect on brain gene expression changes compared with oral rotenone.

\section{Systemic rotenone administration altered brain urea levels}

Brain urea levels can be used to estimate brain energy metabolism, especially with regard to neurodegenerative diseases. Hence we evaluated striatal urea levels in rotenone-treated rats. Urea was significantly upregulated in Rot-3-ip and Rot-50-po striatum compared with their respective controls (Figure 4). Thus, rotenone markedly dysregulated striatal energy homeostasis. There was no difference ( $p>0.05)$ between the Rot-3-ip and Rot-50-po groups. To the best of our knowledge this is the first report to show PD-associated brain urea changes.
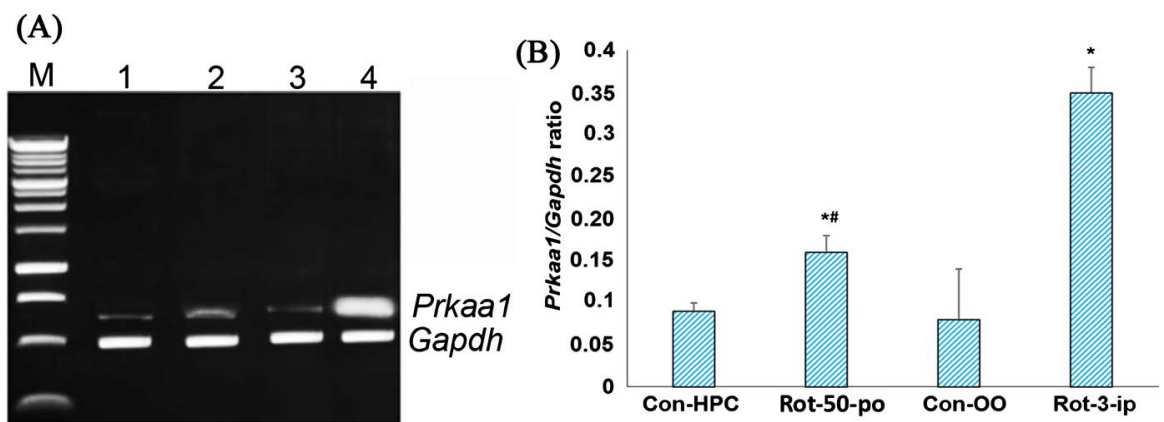

Figure 3. Prkaal gene expression in the striatum of control and rotenone-treated groups. (A) Representative agarose gel of reverse-transcription polymerase chain reaction (RTPCR) products for Prkaal and Gapdh (loading control). (B) Quantification of gel bands, expressed as the Prkaal/Gapdh ratio ( $\mathrm{n}=6$ rats per group). Lane identities: M, Marker (100 - $1000 \mathrm{bp}$ ); 1, Control hydroxy propyl cellulose (Con-HPC); 2, Rotenone $50 \mathrm{mg} / \mathrm{kg}$ body weight oral (Rot-50-po); 3, Control olive oil (Con-OO); 4, Rotenone $3 \mathrm{mg} / \mathrm{kg}$ body weight intraperitoneal (Rot-3-ip). Statistical analysis: ${ }^{\star} \mathrm{p}<0.01$ compared with Con-OO; ${ }^{*} \mathrm{p}<0.05$ compared with Con-HPC.

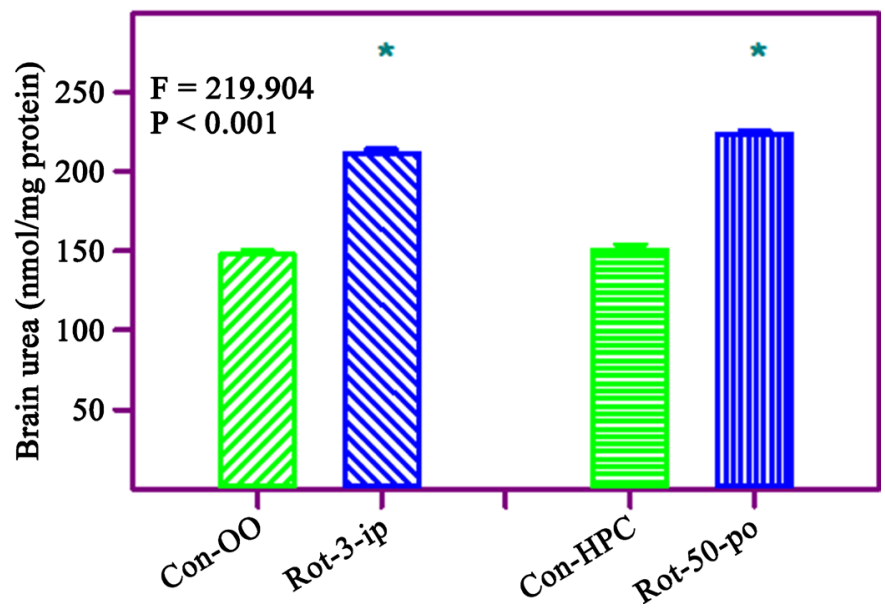

Figure 4. The effect of rotenone on urea levels in the striatum. Values represent mean \pm standard deviation ( $n=6$ rats per group). The "F" and "P" values are from one-way analysis of variance with Student-Newman-Keul multiple comparison test. ${ }^{\star}$ Significantly different from the respective control group. 


\section{Histopathological changes in liver and brain}

We next examined histological changes in the liver and brain due to systemic rotenone administration. In control rats, H\&E-stained liver sections showed normal hepatic cells with well-preserved cytoplasm, prominent nuclei, and normal architecture (Figure 5(A)). Comparatively, daily Rot-3-ip treatment induced single-cell necrosis, inflammation in myriad centrilobular areas adjacent to central veins, and slight diffuse cytoplasmic hepatocellular vacuolization and

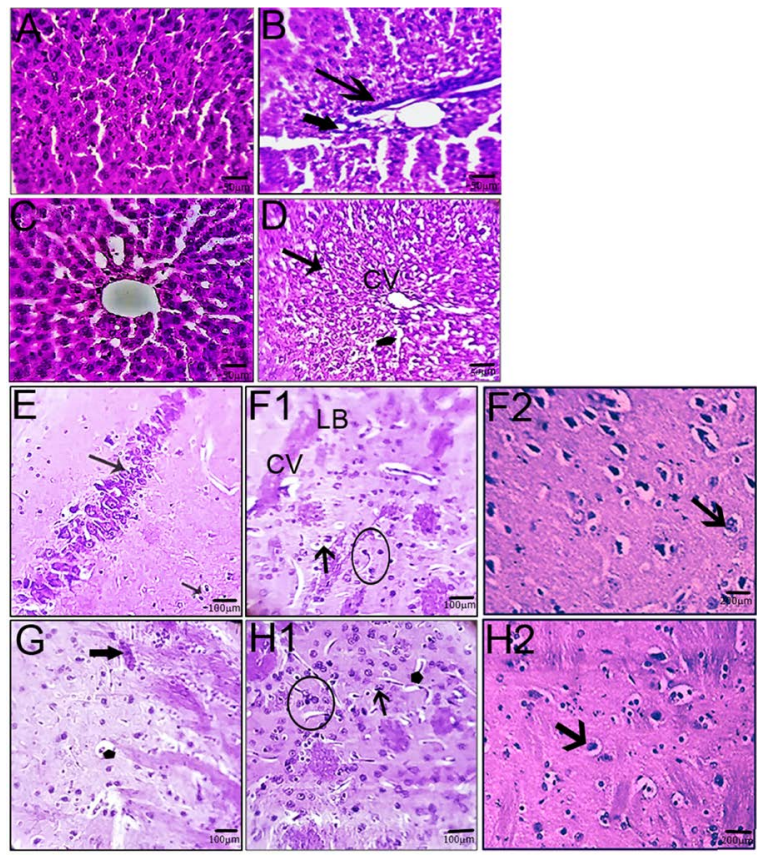

Figure 5. Light microscopic examination of H\&E-stained liver (A)-(D) and brain (E)-(H) tissues. (A) Control olive oil (Con-OO) liver sections revealed the presence of normal hepatic cells with well-preserved cytoplasm, prominent nuclei (small arrow), and normal architecture. (B) Rotenone $3 \mathrm{mg} / \mathrm{kg}$ body weight intraperitoneal (Rot-3-ip) liver showed single cell necrosis (long arrow) and occasional focal widening of the perivenous centrilobular spaces (thick arrow) indicating loss of centrilobular hepatocytes and hepatic inflammation. (C) Control hydroxy propyl cellulose (Con-HPC) liver had normal architecture. (D) Rotenone $50 \mathrm{mg} / \mathrm{kg}$ body weight oral (Rot-50-po) showed inflammation in numerous centrilobular areas adjacent to the central veins (CV), along with slight diffuse cytoplasmic hepatocellular vacuolation (long arrow) and occasional focal widening of the perivenous centrilobular spaces (arrow head). (E) Con-OO brain had normal neuronal cell architecture with prominent nuclei (small arrow), cytoplasm, and normal striatal architecture (long arrow). (F) Rot-3-ip showed marked cytoplasmic vacuolation (CV) neuronal degeneration; neurons were decreased in number and had indistinct boundaries (circle). The sections also exhibited irregular damaged cells and cytoplasmic shrinkage (small arrow), pyknotic nuclei, and Lewy bodies (arrows). (G) Con-HPC showed dark staining in the corpus striatum regions (thick arrow). There was also evidence of perineuronal vacuolation (arrow head). (H) Rot-50-po treatment showed marked striatal neurodegeneration with shrunken (circle) and distorted neurons (arrow heads), pericellular haloes, apoptotic cells (long arrow), inflammation, and hemorrhage. The arrow heads in panels F1, F2, H1, and H2 indicate the presence of Lewy bodies in Rot-3-ip and Rot-50-po groups, respectively. Magnification: Panel A-D: 45×; Panel E: 20×; Panel F2, H2: 60×; Panel F1, H1 and G: 45×. 
occasional focal widening of the perivenous centrilobular spaces (Figure 5(B)). Examination of H\&E-strained liver sections from Con-HPC rats revealed normal hepatic cells with well-preserved cytoplasm, prominent nuclei, and normal architecture (Figure 5(C)). Rot-50-po rats had occasional focal widening of the perivenous centrilobular spaces, a finding that suggests a minimal loss of centrilobular hepatocytes (Figure 5(D)).

Rotenone administered intraperitoneally or orally crosses the blood-brainbarrier and induces PD-like symptoms. Thus, we examined histopathological changes in the striatum. In control rats, striatal sections exhibited normal neuronal cells with prominent nuclei, cytoplasm, and normal architecture (Figure 5(E)). Twenty-one days of Rot-3-ip induced marked cytoplasmic vacuolization, neuronal degeneration, pyknotic nuclei, Lewy body formation, necrosis, and perineuronal vacuolization (Figure $5(\mathrm{~F})$ ); these abnormalities are all signs of $\mathrm{PD}$. Oral rotenone treatment induced neuronal damage in the cortico-striatal brain region. The brain striatum sections of Con-HPC rats showed the presence of normal neuronal cells with prominent nuclei, cytoplasm, and normal architecture (Figure 5(G)). Rot-50-po rats showed marked cytoplasmic vacuolization, neuronal degeneration, and Lewy body formation (Figure 5(H)). Earlier works had shown that 28 days of oral rotenone treatment to C57BL/6 mice promoted $\mathrm{PD}$ features in the brain; our work involving Wistar rats is in agreement with those findings [32] [39]. Notably, oral administration of rotenone (30 mg/kg bw) to $\mathrm{C} 57 \mathrm{BL} / 6$ mice for 56 days caused degeneration of nigrostriatal dopaminergic neurons and motor deficits with increased cytoplasmic $\alpha$-syn protein [40]. Even paraquat (10.2 and $15.6 \mathrm{mg} \mathrm{PQ}$ ion/kg body weight/day) exposure to C57BL/6J mice through diet for 13 continuous weeks did not cause damage to dopaminergic neurons in the SNpc, a finding that is quite interesting [41].

Immunohistochemical analysis of $a$-syn and tyrosine hydroxylase in the brain from rotenone-induced PD rats

The $\alpha$-syn protein expression was significantly $(\mathrm{p}<0.05)$ elevated in the striatum of both Rot-3-ip (Figure 6(B)) and Rot-50-po (Figure 6(D)) groups compared with the respective controls (Figure 6(A) and Figure 6(C)). Conversely, tyrosine hydroxylase was significantly $(\mathrm{p}<0.05)$ reduced in both Rot-3-ip (Figure 7(B)) and Rot-50-po (Figure 7(D)) groups compared with the respective controls (Figure 7(A) and Figure 7(C)). $\alpha$-Syn was higher in the Rot-3-ip group compared with the Rot-50-po group. Consistent with this trend, tyrosine hydroxylase was apparently more severely reduced in Rot-3-ip compared with Rot-50-po striatum. Overall, these protein expression alterations suggest that intraperitoneal rather than oral rotenone administration more strongly induced the striatal PD pathology in rats.

\section{Discussion}

Rotenone-induced PD models have been widely used to understand the events associated with disease etiology as well as to test the efficacy of therapeutic 

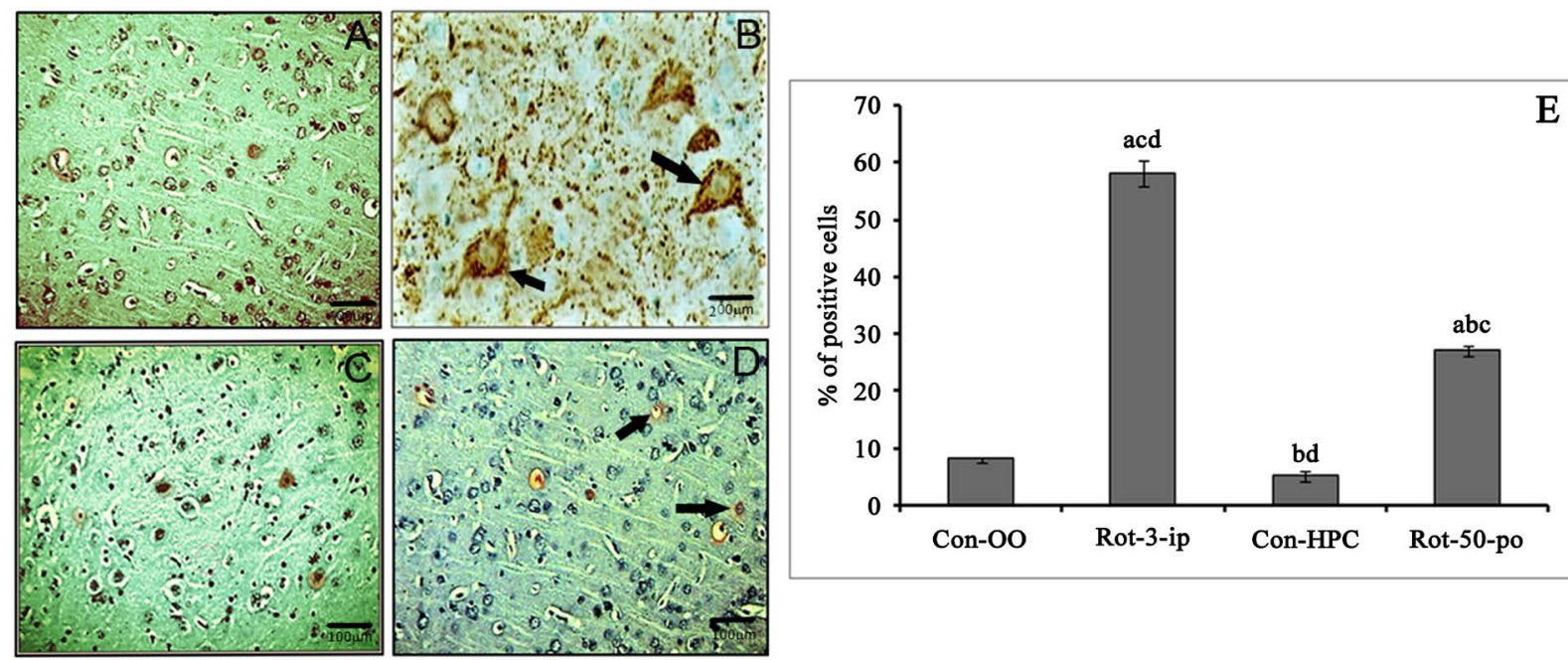

Figure 6. The effect of systemic rotenone administration on $\alpha$-synuclein protein expression. $\alpha$-Synuclein immunostaining in the striatum from (A) Control olive oil (Con-OO), (B) Rotenone $3 \mathrm{mg} / \mathrm{kg}$ body weight intraperitoneal (Rot-3-ip), (C) Control hydroxy propyl cellulose (Con-HPC), and (D) Rotenone $50 \mathrm{mg} / \mathrm{kg}$ body weight oral (Rot-50-po) rats. The arrows denote the expression of $\alpha$-synuclein protein. (E) Quantitative analysis of $\alpha$-synuclein protein expression. Results are expressed as the mean + standard error of the mean $(n=6$ rats per group). The statistical analysis was carried out by employing one-way analysis of variance followed by Bonferroni multiple comparison test $(\mathrm{p}<0.05$ was considered significant). The lowercase letters indicate the following: a, significantly different from Con-OO; $b$, significantly different from Rot-3-ip; c, significantly different from Con-HPC; and d, significantly different from Rot-50-po. The numbers for the groups indicate the dosage $(\mathrm{mg} / \mathrm{kg}$ body weight).

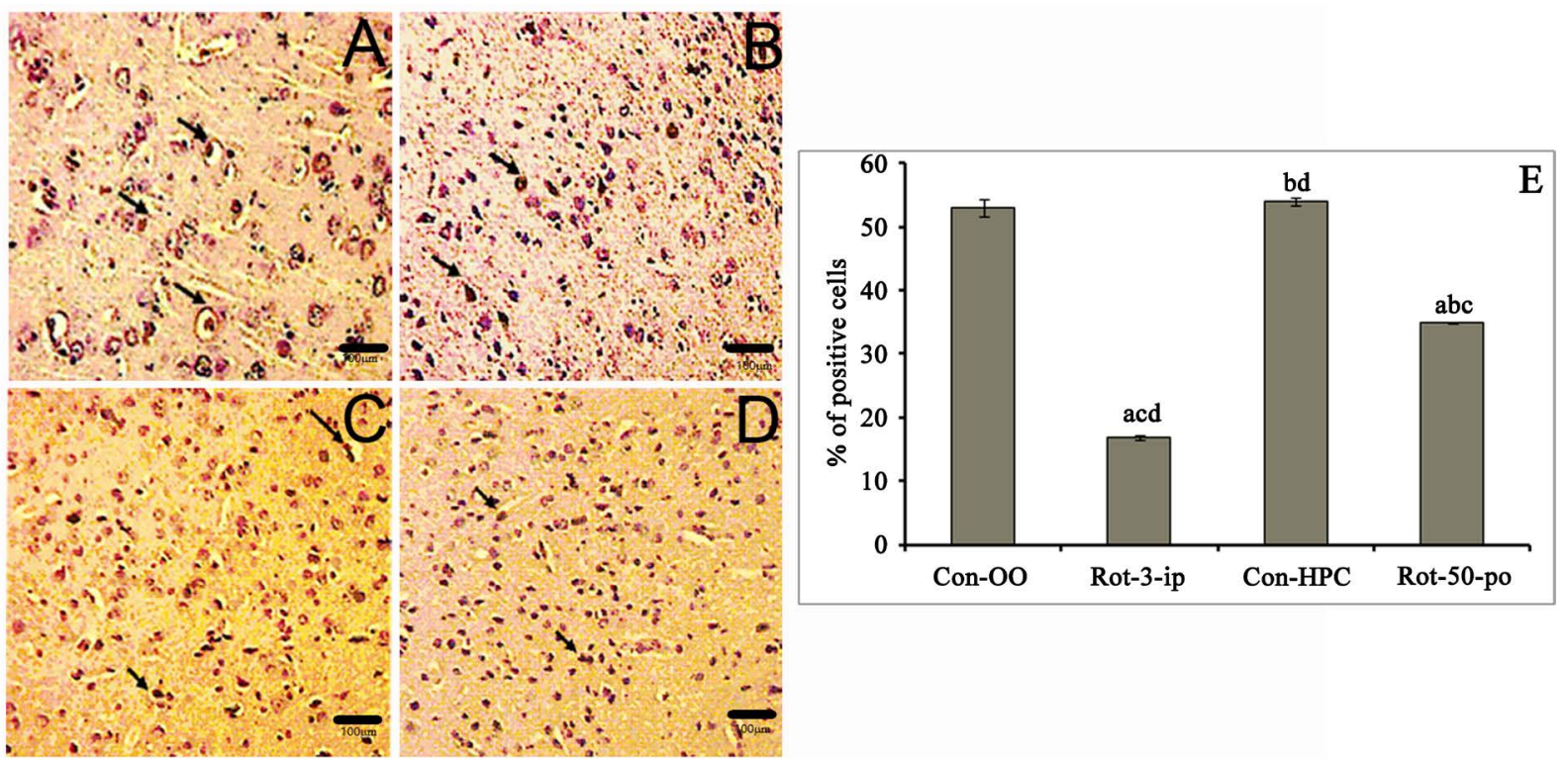

Figure 7. The effect of systemic rotenone administration on tyrosine hydroxylase protein expression. Tyrosine hydroxylase immunostaining in the striatum from (A) Control olive oil (Con-OO), (B) Rotenone $3 \mathrm{mg} / \mathrm{kg}$ body weight intraperitoneal (Rot-3-ip), (C) Control hydroxy propyl cellulose (Con-HPC), and (D) Rotenone $50 \mathrm{mg} / \mathrm{kg}$ body weight oral (Rot-50-po) rats. The arrows denote the expression of tyrosine hydroxylase protein. (E) Quantitative analysis of tyrosine hydroxylase protein expression. Results are expressed as the mean \pm standard error of the mean ( $n=6$ rats each group). The statistical analysis was carried out by employing one-way analysis of variance followed by Bonferroni multiple comparison test ( $\mathrm{p}<0.05$ was considered significant). The lowercase letters indicate the following: a, significantly different from Con-OO; b, significantly different from Rot-3-ip; c, significantly different from Con-HPC; and d, significantly different from Rot-50-po. The numbers for the groups indicate the dosage ( $\mathrm{mg} / \mathrm{kg}$ body weight). 
agents. However, there is inconsistency with regard to the dosage and route of administration required for optimal PD modeling in rats or mice either by intraperitoneal (2 - $3 \mathrm{mg} / \mathrm{kg} \mathrm{bw}$ ) or oral (10 - $50 \mathrm{mg} / \mathrm{kg} \mathrm{bw}$ ) rotenone (according to the literature). Some problems with rotenone-induced PD models are high mortality and replication difficulties [42]. In our study, intraperitoneal rotenone caused minimal mortality (33\% died), whereas oral rotenone resulted in no mortality.

In the present work, we explored whether intraperitoneal and oral rotenone administration promoted differential PD pathology in male Wistar rats. We examined markers commonly associated with PD etiology: $\alpha$-syn and tyrosine hydroxylase protein expression in the corpus striatum, gene expression changes (Snca, Becn1, and Pkka1 in the striatum), and striatal urea levels. Overall, intraperitoneal rotenone more robustly influenced brain gene expression levels than oral administration. Further, intraperitoneal rotenone markedly increased striatal $\alpha$-syn-positive and reduced tyrosine-hydroxylase-positive neurons compared with oral administration. Given that rotenone is a highly lipophilic compound, it easily crosses the blood-brain barrier [43]. Perhaps intraperitoneal rotenone more efficiently reaches the striatum than when it is administered orally. The induced gene and protein expression changes are highly associated with PD and thus serve as an effective model to study the disease process.

In earlier work, increased beclin- 1 and $\alpha$-syn protein expression were reported in rotenone-induced PC12 cell cultures [44] and in rat substantia nigra after subcutaneous rotenone administration [14]. Intraperitoneal rotenone administration appeared to upregulate beclin-1 more than oral administration. Intriguingly, beclin-1 gene transfer activated autophagy and ameliorated the $\alpha$-synmediated neuropathology in a transgenic mouse model [45]. Further, beclin-1 and high mobility group box 1 (HMGB1) improved the autophagy inhibition mediated by $\alpha$-syn accumulation in PC12 cells [46]. Autophagy may provide energy from the degraded products when nutrients (and thus energy) are scare [47]. Thus, the concomitant increases in $\alpha$-syn and beclin- 1 in the striatum may indicate a potential mechanism to clear $\alpha$-syn and provide energy from the degradation products in the $\alpha$-syn-affected cells.

Depletion of adenosine triphosphate (ATP) or a condition such as glucose starvation could activate AMPK. Hence, AMPK plays an important role in cell survival and is involved in energy homeostasis and autophagy [48]. AMPK activation in the brain may improve energy metabolism as well as protein clearance in vascular injury or neurodegenerative conditions [49] [50]. While both intraperitoneal- and oral-rotenone-induced PD significantly elevated AMPK gene expression, the effect was much more robust for intraperitoneal administration. Given the beclin-1 was upregulated upon intraperitoneal- and oral-rotenone-induced $\mathrm{PD}$, the upregulated AMPK and beclin-1 gene expression seen in PD-induced rats could be an indication for energy homeostasis mechanisms activated to overcome the ATP deficits [51] [52] [53]. Given the extended administration 
time, these methods may provide some sort of energy compensation

Interestingly, oral rotenone upregulated Snca more modestly compared with intraperitoneal administration. The gene expression changes correlated with the immunohistochemistry findings, where there was a greater percentage of $\alpha$-synpositive cells in Rot-3-ip-treated compared with Rot-50-po-treated striatum. These data may suggest that intraperitoneal rotenone causes greater $\alpha$-syn accumulation.

There are a few possibilities as to why intraperitoneal rotenone produced more toxicity compared with oral rotenone. Drugs and pharmaceuticals are degraded and modified in the gastrointestinal tract. It is possible that the intraperitoneally administered rotenone might have been metabolized to more toxic forms compared with orally administered rotenone. This eventuality might partially explain the more robust Becn1, Snca, and Prkaal expression changes after intraperitoneal compared with oral rotenone administration. Experimental studies have revealed that the absorption of small-to-medium sized molecules (molecular weight $<5000 \mathrm{Da}$ ) and fluids occurs predominantly from the visceral peritoneum by diffusion through the splenic, inferior, and superior mesenteric capillaries, which later drain into the portal vein [54]. There is very limited retrograde movement of both small and large molecules from capillaries to the peritoneal cavity after the systemic administration of a drug; thus, the overall absorption of pharmacological agents from the peritoneal cavity to systemic circulation is not highly disturbed [55] [56]. This eventuality might also partly explain why intraperitoneal rotenone was more toxic than oral rotenone.

While the brain striatal urea levels were significantly increased after intraperitoneal or oral rotenone administration compared with the respective controls, there was no striking difference between the treatment methods. Significantly elevated urea levels are indicative of altered energy metabolism and protein catabolism in PD rats. Hence, this finding could suggest an altered urea cycle pathway in the PD condition. The study findings also provide insights into energy related mitochondrial abnormalities of $\mathrm{PD}$ and speculate the possible role of mitochondrial quality control mechanisms (MAGIC: Mitochondria As Guardian In Cytosol) in clearing $\alpha$-syn protein aggregates [57] [58] through amino acid catabolism and urea cycle activation. Elevated brain urea levels and activation of the urea cycle/ammonia formation occurs in many neurodegenerative diseases, including $\mathrm{AD}$ and HD [59]-[64]. Several lines of research have indicated that $\mathrm{AD}, \mathrm{PD}$, and $\mathrm{HD}$ brains exhibit hypometabolism and are vulnerable to high energy demand due to poor glycolysis and mitochondrial TCA cycle.

\section{Conclusion}

In conclusion, our data indicate that subchronic systemic rotenone administration induced notable $\alpha$-syn and tyrosine peroxidase levels in the corpus striatum, data that are indicative of rotenone-induced neuronal damage. Gene expression changes in autophagy- and energy-homeostasis-related genes as well as urea le- 
vels suggest the rotenone impairs normal cellular processes. Intriguingly, there were apparent differences between intraperitoneal and oral rotenone administration, where the former method more robustly affected these measures.

\section{Acknowledgements}

The authors sincerely thank Dr. Jahanbanoo Shahryari, Stanford University School of Medicine, for providing her valuable inputs to histopathological analysis. We thank Bright Care Research Centre Pvt Ltd. for extending their facility support for immunohistochemistry and RT-PCR studies. We also thank S. Madhankumar and S. Praveenkumar, lab technicians for their technical support during animal experiments.

\section{Conflicts of Interest}

The authors declare no conflicts of interest regarding the publication of this paper.

\section{References}

[1] Sherer, T.B., Betarbet, R., Testa, C.M., Seo, B.B., Richardson, J.R., Kim, J.H., Miller, G.W., Yagi, T., Matsuno-Yagi, A. and Greenamyre, J.T. (2003) Mechanism of Toxicity in Rotenone Models of Parkinson's Disease. Journal of Neuroscience, 23, 1075610764. https://doi.org/10.1523/JNEUROSCI.23-34-10756.2003

[2] Bobela, W., Nazeeruddin, S., Knott, G., Aebischer, P. and Schneider, B.L. (2017) Modulating the Catalytic Activity of AMPK Has Neuroprotective Effects against $\alpha$-Synuclein Toxicity. Molecular Neurodegeneration, 12, 80 . https://doi.org/10.1186/s13024-017-0220-X

[3] Cortes, C.J. and La Spada, A.R. (2019) TFEB Dysregulation as a Driver of Autophagy Dysfunction in Neurodegenerative Disease: Molecular Mechanisms, Cellular Processes, and Emerging Therapeutic Opportunities. Neurobiology of Disease, 122, 83 93. https://doi.org/10.1016/j.nbd.2018.05.012

[4] Sheehan, P. and Yue, Z. (2019) Deregulation of Autophagy and Vesicle Trafficking in Parkinson's Disease. Neuroscience Letters, 697, 59-65. https://doi.org/10.1016/j.neulet.2018.04.013

[5] Ma, P., Yun, J., Deng, H. and Guo, M. (2018) Atg1 Mediated Autophagy Suppresses Tissue Degeneration in pink1/parkin Mutants by Promoting Mitochondrial Fission in Drosophila. Molecular Biology of the Cell, 29, 3082-3092. https://doi.org/10.1091/mbc.E18-04-0243

[6] Garcia-Esparcia, P., Koneti, A., Rodríguez-Oroz, M.C., Gago, B., Del Rio, J.A. and Ferrer, I. (2018) Mitochondrial Activity in the Frontal Cortex Area 8 and Angular Gyrus in Parkinson's Disease and Parkinson's Disease with Dementia. Brain Pathology, 28, 43-57. https://doi.org/10.1111/bpa.12474

[7] Van Laar, V.S. and Berman, S.B. (2013) The Interplay of Neuronal Mitochondrial Dynamics and Bioenergetics: Implications for Parkinson's Disease. Neurobiology of Disease, 51, 43-55. https://doi.org/10.1016/j.nbd.2012.05.015

[8] Drolet, R.E., Cannon, J.R., Montero, L. and Greenamyre, J.T. (2009) Chronic Rotenone Exposure Reproduces Parkinson's Disease Gastrointestinal Neuropathology. Neurobiology of Disease, 36, 96-102. https://doi.org/10.1016/j.nbd.2009.06.017

[9] Pan-Montojo, F., Anichtchik, O., Dening, Y., Knels, L., Pursche, S., Jung, R., Jack- 
son, S., Gille, G., Spillantini, M.G., Reichmann, H. and Funk, R.H. (2010) Progression of Parkinson's Disease Pathology Is Reproduced by Intragastric Administration of Rotenone in Mice. PLOS ONE, 5, e8762.

https://doi.org/10.1371/journal.pone.0008762

[10] Rocha, E.M., De Miranda, B. and Sanders, L.H. (2018) Alpha-Synuclein: Pathology, Mitochondrial Dysfunction and Neuroinflammation in Parkinson's Disease. Neurobiology of Disease, 109, 249-257. https://doi.org/10.1016/j.nbd.2017.04.004

[11] Fan, Z., Pan, Y.T., Zhang, Z.Y., Yang, H., Yu, S.Y., Zheng, Y., et al. (2020) Systemic Activation of NLRP3 Inflammasome and Plasma $\alpha$-Synuclein Levels Are Correlated with Motor Severity and Progression in Parkinson's Disease. Journal of Neuroinflammation, 17, 11. https://doi.org/10.1186/s12974-019-1670-6

[12] Lahooti, B., Chhibber, T., Bagchi, S., Pooja Varahachalam, S. and Jayant, R.D. (2020) Therapeutic Role of Inflammasome Inhibitors in Neurodegenerative Disorders. Brain, Behavior, and Immunity. https://doi.org/10.1016/j.bbi.2020.11.004

[13] Malik, B.R., Maddison, D.C., Smith, G.A. and Peters, O.M. (2019) Autophagic and Endo-Lysosomal Dysfunction in Neurodegenerative Disease. Molecular Brain, 12, 100. https://doi.org/10.1186/s13041-019-0504-x

[14] Liu, B., Sun, J., Zhang, J., Mao, W., Ma, Y., Li, S., Cheng, X. and Lv, C. (2015) Autophagy-Related Protein Expression in the Substantia Nigra and Eldepryl Intervention in Rat Models of Parkinson's Disease. Brain Research, 1625, 180-188. https://doi.org/10.1016/j.brainres.2015.08.033

[15] Hang, L., Thundyil, J. and Lim, K.L. (2015) Mitochondrial Dysfunction and Parkinson Disease: A Parkin-AMPK Alliance in Neuroprotection. Annals of the New York Academy of Sciences, 1350, 37-47. https://doi.org/10.1111/nyas.12820

[16] Qin, Y., Qiu, J., Wang, P., Liu, J., Zhao, Y., Jiang, F. and Lou, H. (2020) Impaired Autophagy in Microglia Aggravates Dopaminergic Neurodegeneration by Regulating NLRP3 Inflammasome Activation in Experimental Models of Parkinson's Disease. Brain, Behavior, and Immunity. https://doi.org/10.1016/j.bbi.2020.10.010

[17] Prasad, E.M. and Hung, S.Y. (2020) Behavioral Tests in Neurotoxin-Induced Animal Models of Parkinson's Disease. Antioxidants (Basel), 9, 1007. https://doi.org/10.3390/antiox9101007

[18] Blesa, J., Trigo-Damas, I., Quiroga-Varela, A. and Jackson-Lewis, V.R. (2015) Oxidative Stress and Parkinson's Disease. Frontiers in Neuroanatomy, 9, 91. https://doi.org/10.3389/fnana.2015.00091

[19] Dias, V., Junn, E. and Mouradian, M.M. (2013) The Role of Oxidative Stress in Parkinson's Disease. Journal of Parkinson's Disease, 3, 461-491. https://doi.org/10.3233/JPD-130230

[20] Drechsel, D.A. and Patel, M. (2008) Role of Reactive Oxygen Species in the Neurotoxicity of Environmental Agents Implicated in Parkinson's Disease. Free Radical Biology and Medicine, 44, 1873-1886. https://doi.org/10.1016/j.freeradbiomed.2008.02.008

[21] Xiong, N., Huang, J., Zhang, Z., Zhang, Z., Xiong, J., Liu, X., et al. (2009) Stereotaxical Infusion of Rotenone: A Reliable Rodent Model for Parkinson's Disease. PLoS $O N E$, 4, e7878. https://doi.org/10.1371/journal.pone.0007878

[22] Dodiya, H.B., Forsyth, C.B., Voigt, R.M., Engen, P.A., Patel, J., Shaikh, M., et al. (2020) Chronic Stress-Induced Gut Dysfunction Exacerbates Parkinson's Disease Phenotype and Pathology in a Rotenone-Induced Mouse Model of Parkinson's Disease. Neurobiology of Disease, 135, Article ID: 104352. https://doi.org/10.1016/j.nbd.2018.12.012 
[23] Ferrante, R.J., Schulz, J.B., Kowall, N.W. and Beal, M.F. (1997) Systemic Administration of Rotenone Produces Selective Damage in the Striatum and Globus Pallidus, But Not in the Substantia Nigra. Brain Research, 753, 157-162. https://doi.org/10.1016/S0006-8993(97)00008-5

[24] Horst, C.H., Schlemmer, F., de Aguiar Montenegro, N., Domingues, A.C.M., Ferreira, G.G., da Silva Ribeiro, C.Y., et al. (2018) Signature of Aberrantly Expressed microRNAs in the Striatum of Rotenone-Induced Parkinsonian Rats. Neurochemical Research, 43, 2132-2140. https://doi.org/10.1007/s11064-018-2638-0

[25] Inden, M., Kitamura, Y., Tamaki, A., Yanagida, T., Shibaike, T., Yamamoto, A., et al. (2009) Neuroprotective Effect of the Antiparkinsonian Drug Pramipexole against Nigrostriatal Dopaminergic Degeneration in Rotenone-Treated Mice. Neurochemistry International, 55, 760-767. https://doi.org/10.1016/j.neuint.2009.07.009

[26] Inden, M., Kitamura, Y., Abe, M., Tamaki, A., Takata, K. and Taniguchi, T. (2011) Parkinsonian Rotenone Mouse Model: Reevaluation of Long-Term Administration of Rotenone in C57BL/6 Mice. Biological and Pharmaceutical Bulletin, 34, 92-96. https://doi.org/10.1248/bpb.34.92

[27] Sun, C., Wang, Y., Mo, M., Song, C., Wang, X., Chen, S. and Liu, Y. (2019) Minocycline Protects against Rotenone-Induced Neurotoxicity Correlating with Upregulation of Nurr1 in a Parkinson's Disease Rat Model. BioMed Research International, 2019, Article ID: 6843265. https://doi.org/10.1155/2019/6843265

[28] Thanalakshmi, J., Archana, R., Senthilkumar, S., Shakila, R., Pazhanivel, N. and Subhashini, S. (2020) Role of Caloric Vestibular Stimulation in Improvement of Motor Symptoms and Inhibition of Neuronal Degeneration in Rotenone Model of Parkinson's Disease-An Experimental Study. Physiology International. https://doi.org/10.1556/2060.2020.00036

[29] Kavuri, S. and Sivanesan, S. (2019) Evaluation of Haematological Alterations in Intraperitoneal and Oral Rotenone Induced Parkinson's Disease Wistar Rats. International Journal of Pharmaceutical Research \& Allied Sciences, 8, 1-13.

[30] Kavuri, S., Sivanesan, S. and Rajagopalan, V. (2020) Oxidative Stress and Antioxidant Status in Rotenone Induced Rat Model of Parkinson's Disease. International Journal of Research in Pharmaceutical Sciences, 11, 1-5. https://doi.org/10.26452/ijrps.v11i1.1776

[31] Cannon, J.R., Tapias, V., Na, H.M., Honick, A.S., Drolet, R.E. and Greenamyre, J.T. (2009) A Highly Reproducible Rotenone Model of Parkinson's Disease. Neurobiology of Disease, 34, 279-290. https://doi.org/10.1016/j.nbd.2009.01.016

[32] Inden, M., Kitamura, Y., Takeuchi, H., Yanagida, T., Takata, K., Kobayashi, Y., Taniguchi, T., Yoshimoto, K., Kaneko, M., Okuma, Y., Taira, T., Ariga, H. and Shimohama, S. (2007) Neurodegeneration of Mouse Nigrostriatal Dopaminergic System Induced by Repeated Oral Administration of Rotenone Is Prevented by 4-Phenylbutyrate, a Chemical Chaperone. Journal of Neurochemistry, 101, 1491-1504. https://doi.org/10.1111/j.1471-4159.2006.04440.x

[33] Singh, C.K., George, J., Nihal, M., Sabat, G., Kumar, R. and Ahmad, N. (2014) Novel Downstream Molecular Targets of SIRT1 in Melanoma: A Quantitative Proteomics Approach. Oncotarget, 5, 1987-1999. https://doi.org/10.18632/oncotarget.1898

[34] Taguchi, K., Watanabe, Y., Tsujimura, A. and Tanaka, M. (2016) Brain Region-Dependent Differential Expression of Alpha-Synuclein. The Journal of Comparative Neurology, 524, 1236-1258. https://doi.org/10.1002/cne.23901

[35] Liu, L., Meng, T., Wang, Q.S., Jin, H.Z., Sun, Z.Q., Jin, B., Fang, F. and Wang, H.J. (2016) Association of Beclin-1 and microRNA-30a Expression with the Severity and 
Treatment Response of Colorectal Cancer. Genetics and Molecular Research, 15. https://doi.org/10.4238/gmr.15027704

[36] Kim, S.K., Sun, B., Yoon, H., Lee, J.H., Lee, G., Sohn, S.H., Kim, H., Quan, F.S., Shim, I., Ha, J., Min, B.I. and Bae, H. (2014) Expression Levels of the Hypothalamic AMPK Gene Determines the Responsiveness of the Rats to ElectroacupunctureInduced Analgesia. BMC Complementary and Alternative Medicine, 14, 211. https://doi.org/10.1186/1472-6882-14-211

[37] Wang, K., Huang, J., Xie, W., Huang, L., Zhong, C. and Chen, Z. (2016) Beclin1 and HMGB1 Ameliorate the $\alpha$-Synuclein-Mediated Autophagy Inhibition in PC12 Cells. Diagnostic Pathology, 11, 15. https://doi.org/10.1186/s13000-016-0459-5

[38] Huang, J., Yang, J., Shen, Y., Jiang, H., Han, C., Zhang, G., Liu, L., Xu, X., Li, J., Lin, Z., Xiong, N., Zhang, Z., Xiong, J. and Wang, T. (2017) HMGB1 Mediates Autophagy Dysfunction via Perturbing Beclin1-Vps34 Complex in Dopaminergic Cell Model. Frontiers in Molecular Neuroscience, 10, 13.

https://doi.org/10.3389/fnmol.2017.00013

[39] Tasselli, M., Chaumette, T., Paillusson, S., Monnet, Y., Lafoux, A., Huchet-Cadiou, C., Aubert, P., Hunot, S., Derkinderen, P. and Neunlist, M. (2013) Effects of Oral Administration of Rotenone on Gastrointestinal Functions in Mice. Neurogastroenterology and Motility, 25, e183-e193. https://doi.org/10.1111/nmo.12070

[40] Inden, M., Kitamura, Y., Takahashi, K., Takata, K., Ito, N., Niwa, R., et al. (2011) Protection against Dopaminergic Neurodegeneration in Parkinson's Disease-Model Animals by a Modulator of the Oxidized form of DJ-1, a Wild-Type of Familial Parkinson's Disease-Linked PARK7. Journal of Pharmacological Sciences, 117, 189-203. https://doi.org/10.1254/jphs.11151FP

[41] Minnema, D.J., et al. (2014). Dietary Administration of Paraquat for 13 Weeks Does Not Result in a Loss of Dopaminergic Neurons in the Substantia Nigra of C57BL/6J Mice. Regulatory Toxicology and Pharmacology, 68, 250-258. https://doi.org/10.1016/j.yrtph.2013.12.010

[42] Fleming, S.M., Zhu, C., Fernagut, P.O., Mehta, A., DiCarlo, C.D., Seaman, R.L., et al. (2004) Behavioral and Immunohistochemical Effects of Chronic Intravenous and Subcutaneous Infusions of Varying Doses of Rotenone. Experimental Neurology, 187, 418-429. https://doi.org/10.1016/j.expneurol.2004.01.023

[43] Talpade, D.J., Greene, J.G., Higgins, D.S. and Greenamyre, J.T. (2000) In Vivo Labeling of Mitochondrial Complex I (NADH: Ubiquinone Oxidoreductase) in Rat Brain Using [(3)H]dihydrorotenone. Journal of Neurochemistry, 75, 2611-2621.

https://doi.org/10.1046/j.1471-4159.2000.0752611.x

[44] Wu, F., Xu, H.D., Guan, J.J., Hou, Y.S., Gu, J.H., Zhen, X.C. and Qin, Z.H. (2015) Rotenone Impairs Autophagic Flux and Lysosomal Functions in Parkinson's Disease. Neuroscience, 284, 900-911.

https://doi.org/10.1016/j.neuroscience.2014.11.004

[45] Spencer, B., Potkar, R., Trejo, M., Rockenstein, E., Patrick, C., Gindi, R., Adame, A., Wyss-Coray, T. and Masliah, E. (2009) Beclin 1 Gene Transfer Activates Autophagy and Ameliorates the Neurodegenerative Pathology in Alpha-Synuclein Models of Parkinson's and Lewy Body Diseases. Journal of Neuroscience, 29, 13578-13588. https://doi.org/10.1523/JNEUROSCI.4390-09.2009

[46] Wang, B., Abraham, N., Gao, G. and Yang, Q. (2016) Dysregulation of Authophagy and Mitochondrial Function in Parkinson's Disease. Translational Neurodegeneration, 5, 19. https://doi.org/10.1186/s40035-016-0065-1

[47] Singh, R. and Cuervo, A.M. (2011) Autophagy in the Cellular Energetic Balance. Cell 
Metabolism, 13, 495-504. https://doi.org/10.1016/j.cmet.2011.04.004

[48] Shah, S.Z.A., Zhao, D., Hussain, T. and Yang, L. (2017) Role of the AMPK Pathway in Promoting Autophagic Flux via Modulating Mitochondrial Dynamics in Neurodegenerative Diseases: Insight into Prion Diseases. Ageing Research Reviews, 40, 51-63. https://doi.org/10.1016/j.arr.2017.09.004

[49] Vázquez-Manrique, R.P., Farina, F., Cambon, K., Dolores Sequedo, M., Parker, A.J., Millán, J.M., Weiss, A., Déglon, N. and Neri, C. (2016) AMPK Activation Protects from Neuronal Dysfunction and Vulnerability across Nematode, Cellular and Mouse Models of Huntington's Disease. Human Molecular Genetics, 25, 1043-1058. https://doi.org/10.1093/hmg/ddv513

[50] Curry, D.W., Stutz, B., Andrews, Z.B. and Elsworth, J.D. (2018) Targeting AMPK Signaling as a Neuroprotective Strategy in Parkinson's Disease. Journal of Parkinson's Disease, 8, 161-181. https://doi.org/10.3233/JPD-171296

[51] Wang, P., Guan, Y.F., Du, H., Zhai, Q.W., Su, D.F. and Miao, C.Y. (2012) Induction of Autophagy Contributes to the Neuroprotection of Nicotinamide Phosphoribosyltransferase in Cerebral Ischemia. Autophagy, 8, 77-87.

https://doi.org/10.4161/auto.8.1.18274

[52] Xing, S., Zhang, Y., Li, J., Zhang, J., Li, Y., Dang, C., Li, C., Fan, Y., Yu, J., Pei, Z. and Zeng, J. (2012) Beclin 1 Knockdown Inhibits Autophagic Activation and Prevents the Secondary Neurodegenerative Damage in the Ipsilateral Thalamus Following Focal Cerebral Infarction. Autophagy, 8, 63-76. https://doi.org/10.4161/auto.8.1.18217

[53] Hardie, D.G. (2011) AMP-Activated Protein Kinase: An Energy Sensor That Regulates All Aspects of Cell Function. Genes \& Development, 25, 1895-1908. https://doi.org/10.1101/gad.17420111

[54] Williams, R. and White, H. (1986) The Greater Omentum: Its Applicability to Cancer Surgery and Cancer Therapy. Current Problems in Surgery, 23, 789-865. https://doi.org/10.1016/0011-3840(86)90007-9

[55] Flessner, M.F., Dedrick, R.L. and Schultz, J.S. (1985) Exchange of Macromolecules between Peritoneal Cavity and Plasma. American Journal of Physics, 248, H15-H25. https://doi.org/10.1152/ajpheart.1985.248.1.H15

[56] Mactier, R.A. and Khanna, R. (1989) Absorption of Fluid and Solutes from the Peritoneal Cavity. Theoretic and Therapeutic Implications and Applications. ASAIO Transactions, 35, 122-131. https://doi.org/10.1097/00002216-198904000-00002

[57] Li, Y., Xue, Y., Xu, X., Wang, G., Liu, Y., Wu, H., Li, W., Wang, Y., Chen, Z., Zhang, W., Zhu, Y., Ji, W., Xu, T., Liu, L. and Chen, Q. (2019) A Mitochondrial FUNDC1/HSC70 Interaction Organizes the Proteostatic Stress Response at the Risk of Cell Morbidity. EMBO Journal, 38, pii: e98786. https://doi.org/10.15252/embj.201798786

[58] Ruan, L., Zhou, C., Jin, E., Kucharavy, A., Zhang, Y., Wen, Z., Florens, L. and Li, R. (2017) Cytosolic Proteostasis through Importing of Misfolded Proteins into Mitochondria. Nature, 543, 443-446. https://doi.org/10.1038/nature21695

[59] Bensemain, F., Hot, D., Ferreira, S., Dumont, J., Bombois, S., Maurage, C.A., Huot, L., Hermant, X., Levillain, E., Hubans, C., Hansmannel, F., Chapuis, J., Hauw, J.J., Schraen, S., Lemoine, Y., Buée, L., Berr, C., Mann, D., Pasquier, F., Amouyel, P. and Lambert, J.C. (2009) Evidence for Induction of the Ornithine Transcarbamylase Expression in Alzheimer's Disease. Molecular Psychiatry, 14, 106-116. https://doi.org/10.1038/sj.mp.4002089

[60] Hansmannel, F., Sillaire, A., Kamboh, M.I., Lendon, C., Pasquier, F., Hannequin, D., 
Laumet, G., Mounier, A., Ayral, A., DeKosky, S.T., Hauw, D., Berr, C., Mann, D., Amouyel, P., Campion, D. and Lambert, J. (2010) Is the Urea Cycle Involved in Alzheimer's Disease? Journal of Alzheimer's Disease, 21, 1013-1021. https://doi.org/10.3233/JAD-2010-100630

[61] Xu, J., Begley, P., Church, S.J., Patassini, S., Hollywood, K.A., Jüllig, M., Curtis, M.A., Waldvogel, H.J., Faull, R.L.M., Unwin, R.D. and Cooper, G.J.S. (2016) Graded Perturbations of Metabolism in Multiple Regions of Human Brain in Alzheimer's Disease: Snapshot of a Pervasive Metabolic disorder. Biochimica et Biophysica Acta, 1862, 1084-1092. https://doi.org/10.1016/j.bbadis.2016.03.001

[62] Cicolini, J., Jing, Y., Waldvogel, H.J., Faull, R.L.M. and Liu, P. (2016) Urea Cycle Enzymes and Peptidylarginine Deiminase in Alzheimer's Superior Frontal Gyrus. Alzheimer's \& Dementia, 12, 460. https://doi.org/10.1016/j.jalz.2016.06.897

[63] Handley, R.R., Reid, S.J., Brauning, R., Maclean, P., Mears, E.R., Fourie, I., Patassini, S., Cooper, G.J.S., Rudiger, S.R., McLaughlan, C.J., Verma, P.J., Gusella, J.F., MacDonald, M.E., Waldvogel, H.J., Bawden, C.S., Faull, R.L.M. and Snell, R.G. (2017) Brain Urea Increase Is an Early Huntington's Disease Pathogenic Event Observed in a Prodromal Transgenic Sheep Model and HD Cases. Proceedings of the National Academy of Sciences of the United States of America, 114, E11293-E11302. https://doi.org/10.1073/pnas.1711243115

[64] Pattassini, S., Begley, P., Reid, S.J., Church, S.J., Curtis, M., Dragunow, M., Waldvogel, H.J., Unwin, R.D., Snell, R.G., Faull, R.L. and Cooper, G.J. (2015) Identification of Elevated Urea as a Severe, Ubiquitous Metabolic Defect in the Brain of Patients with Huntington's Disease. Biochemical and Biophysical Research Communications, 468, 161-166. https://doi.org/10.1016/j.bbrc.2015.10.140 